\title{
B. Vue d'ensemble des flux financiers et commerciaux entre la Suisse et les pays en développement et les pays en transition
}

Gérard Perroulaz et Xavier Tschumi Canosa

\section{(2) OpenEdition Journals}

Édition électronique

URL : http://journals.openedition.org/aspd/327

DOI : 10.4000/aspd.327

ISSN : 1663-9669

Éditeur

Institut de hautes études internationales et du développement

Édition imprimée

Date de publication : 1 avril 2006

Pagination : 223-233

ISBN : 2-88247-061-4

ISSN : $1660-5934$

Référence électronique

Gérard Perroulaz et Xavier Tschumi Canosa, «B. Vue d'ensemble des flux financiers et commerciaux entre la Suisse et les pays en développement et les pays en transition », Annuaire suisse de politique de développement [En ligne], 25-1 | 2006, mis en ligne le 17 février 2010, consulté le 08 septembre 2020. URL : http://journals.openedition.org/aspd/327 ; DOI : https://doi.org/10.4000/aspd.327 


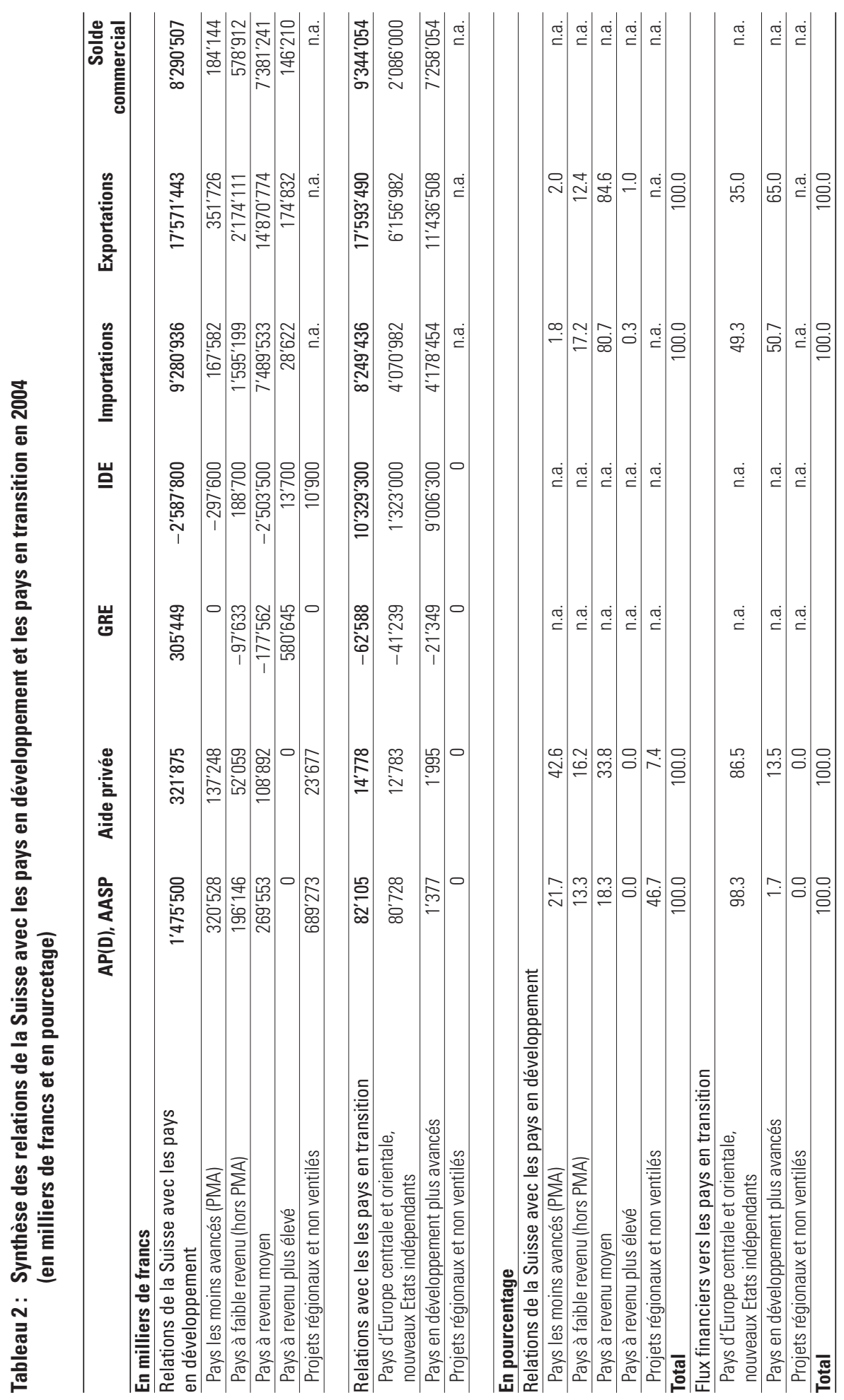



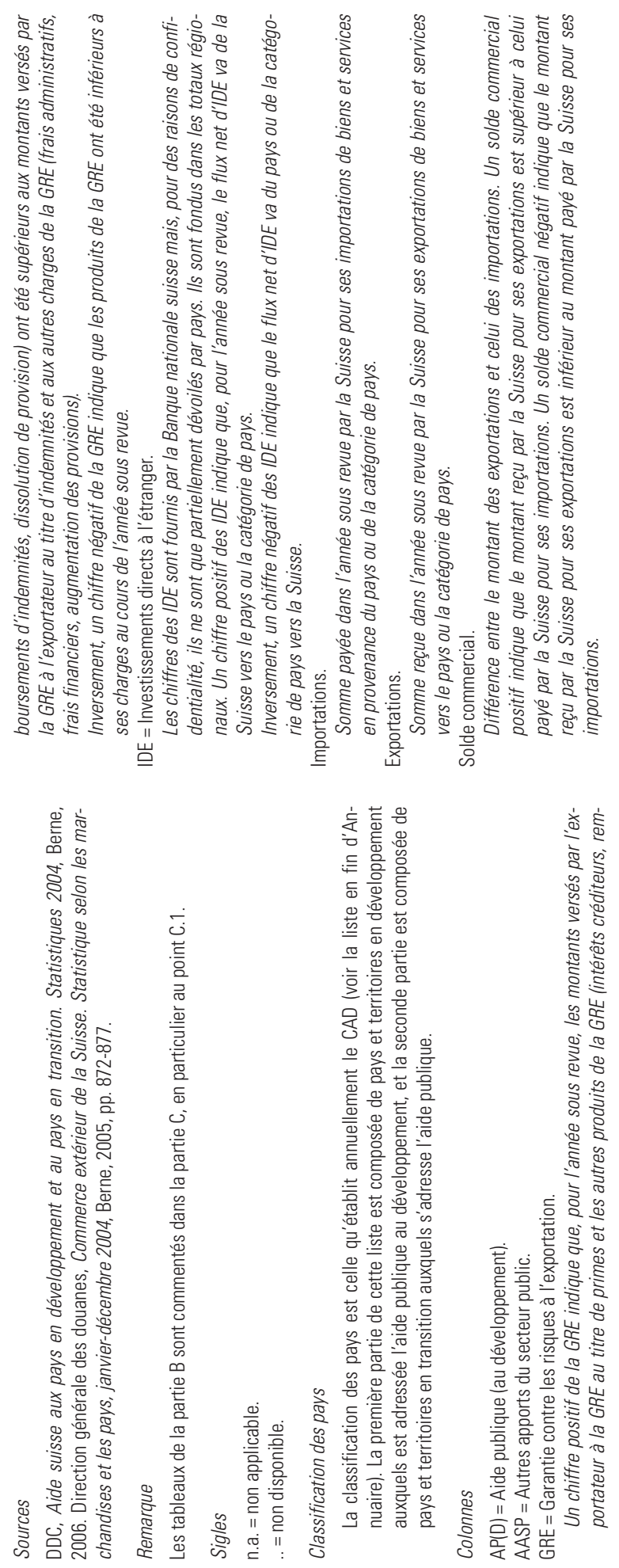


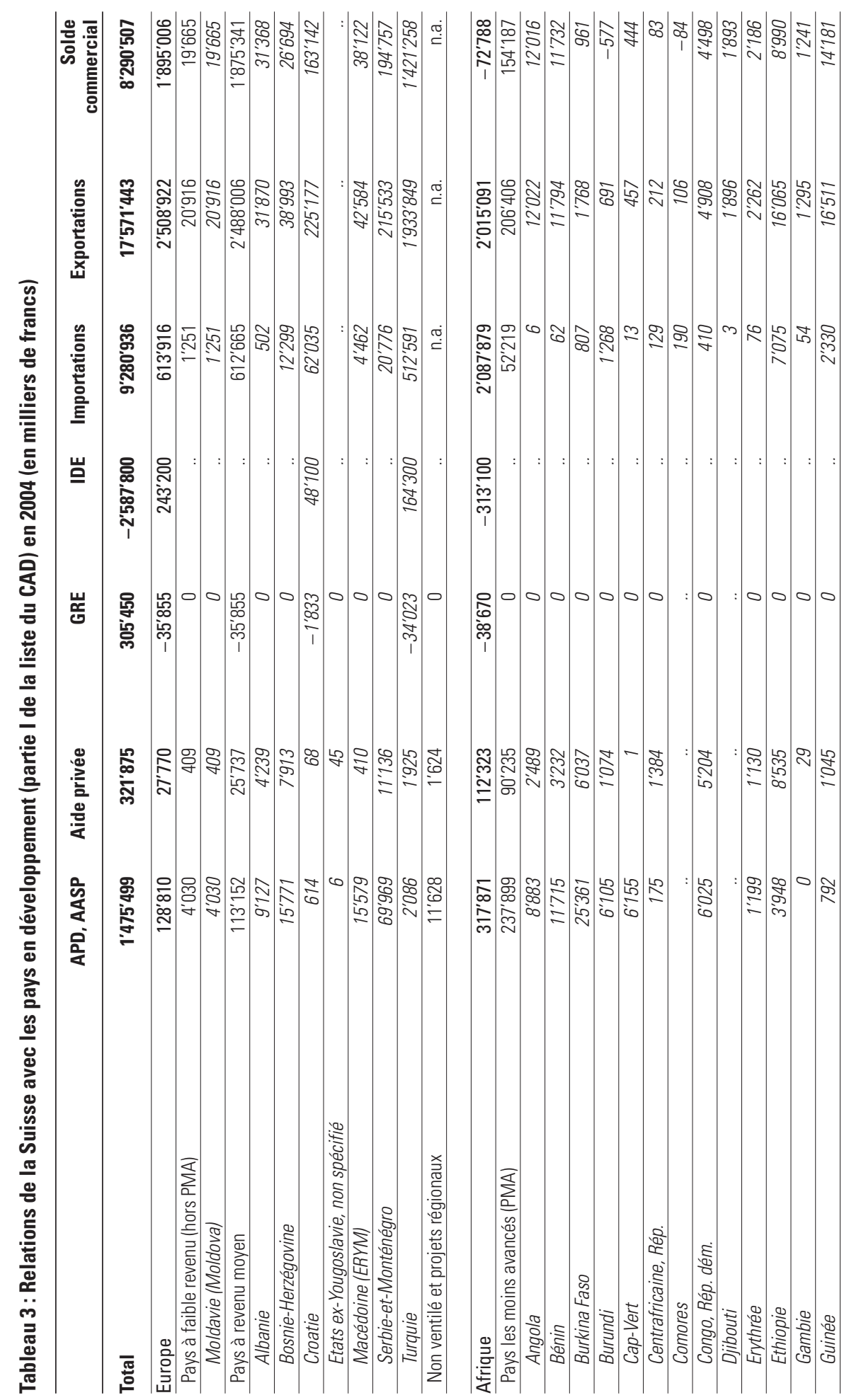




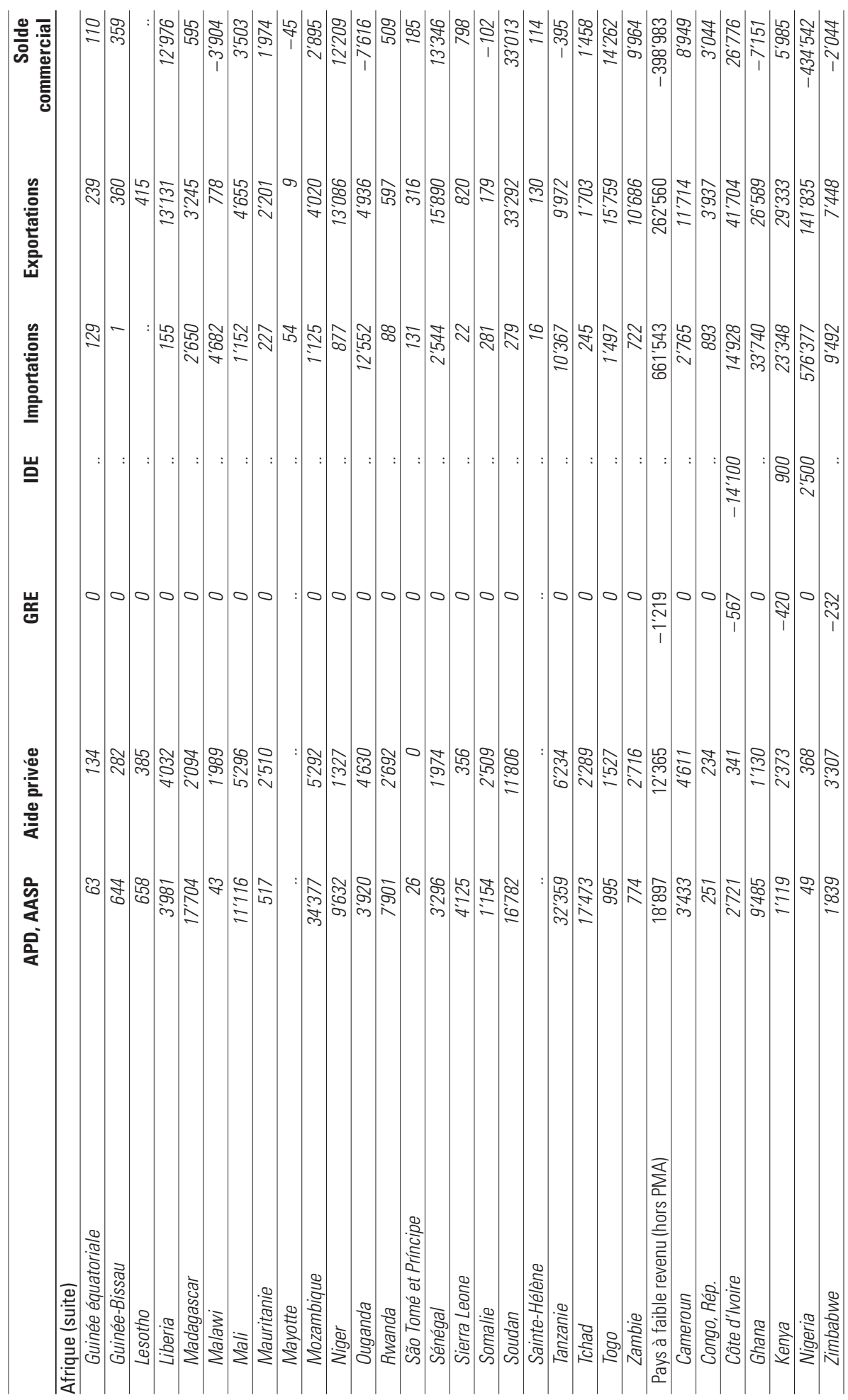




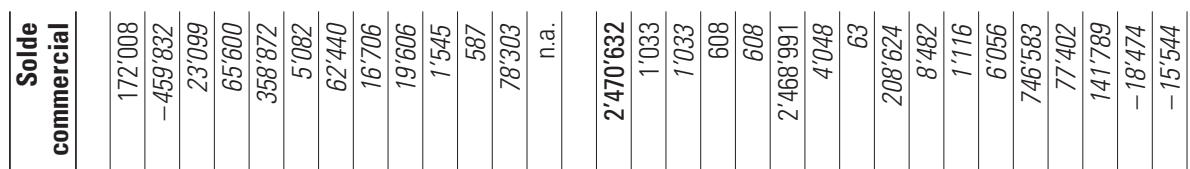

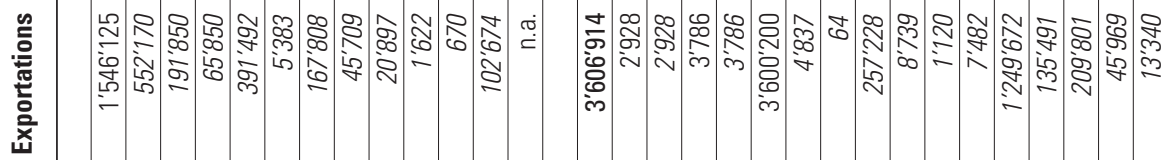

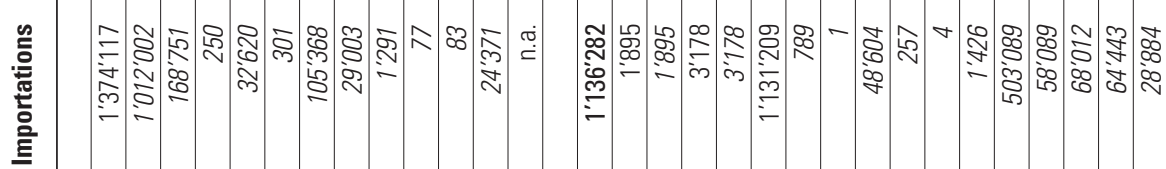

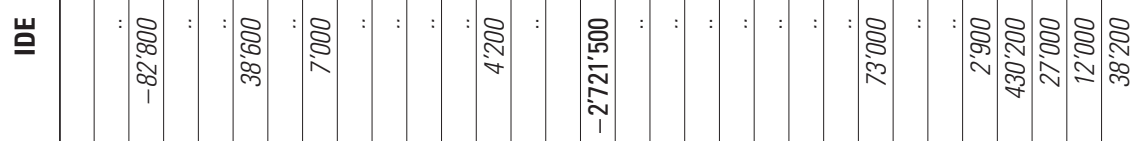

岩

突

高

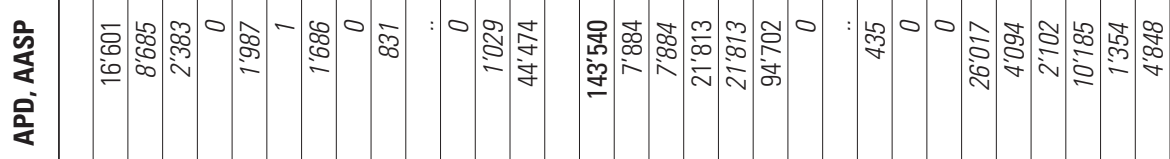

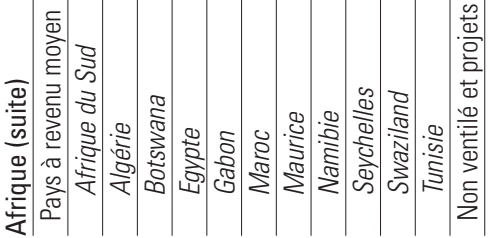

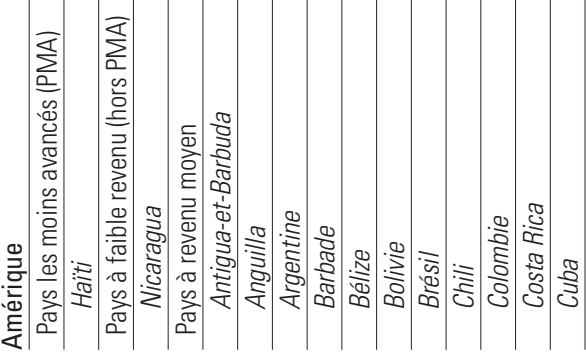




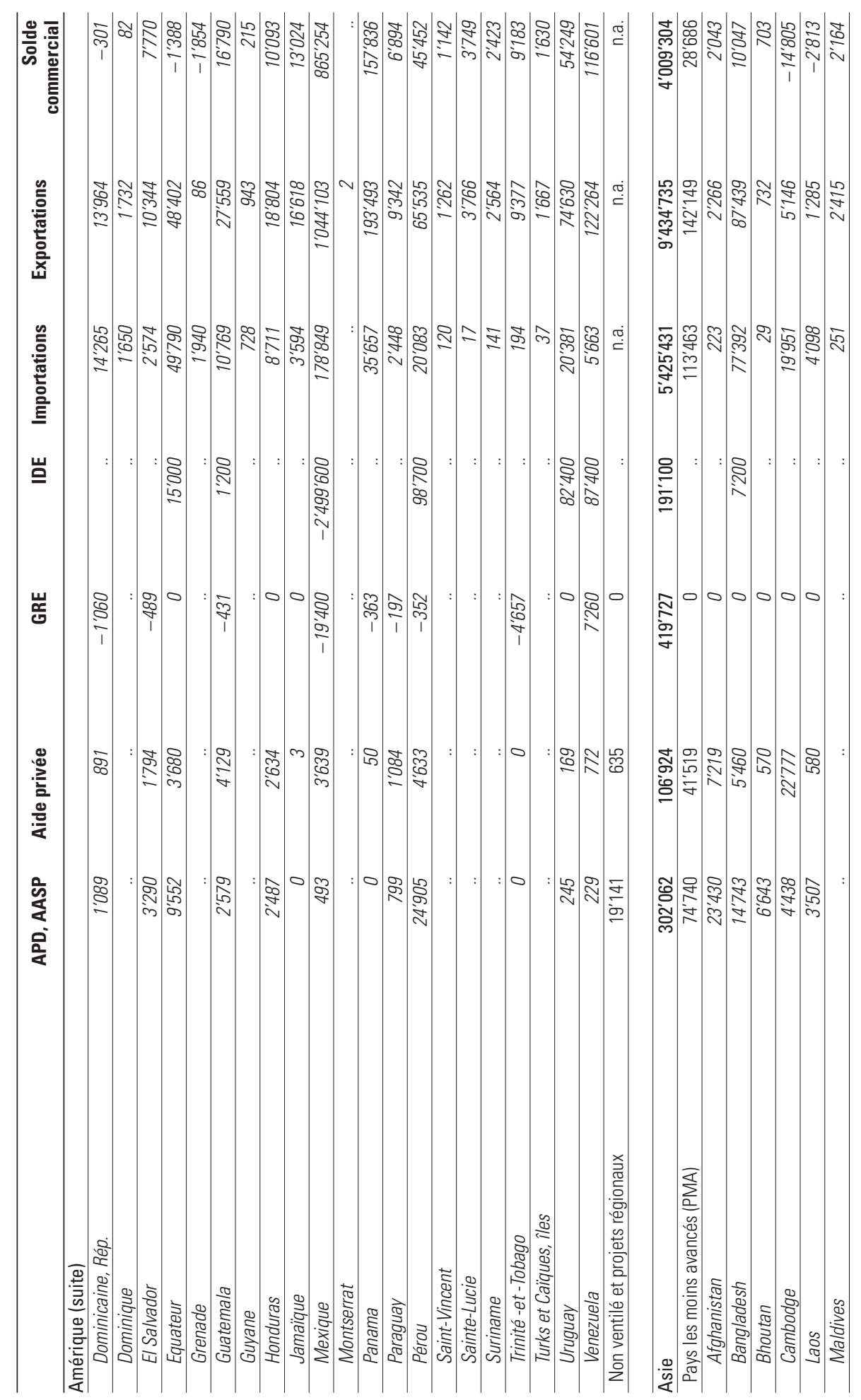




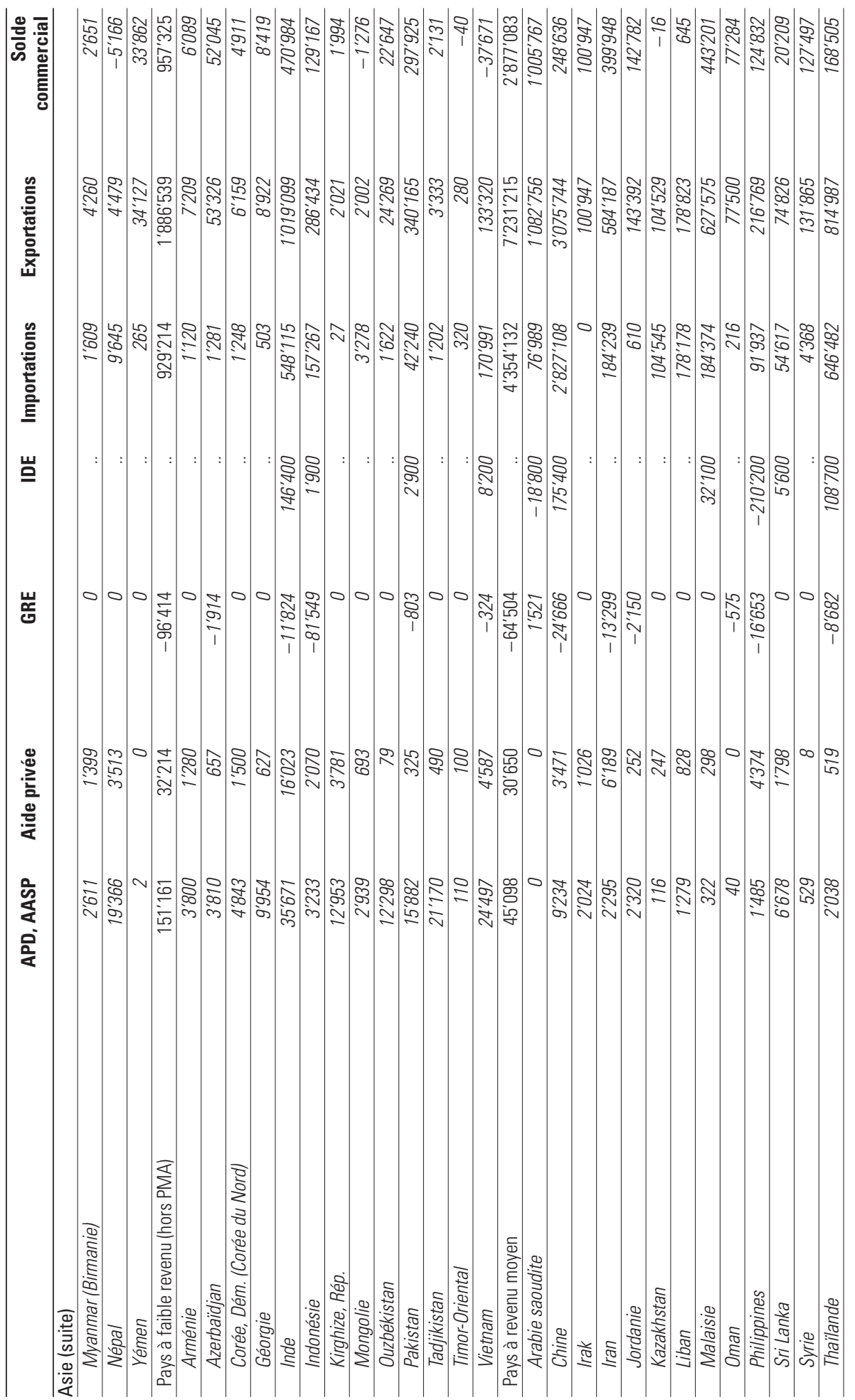




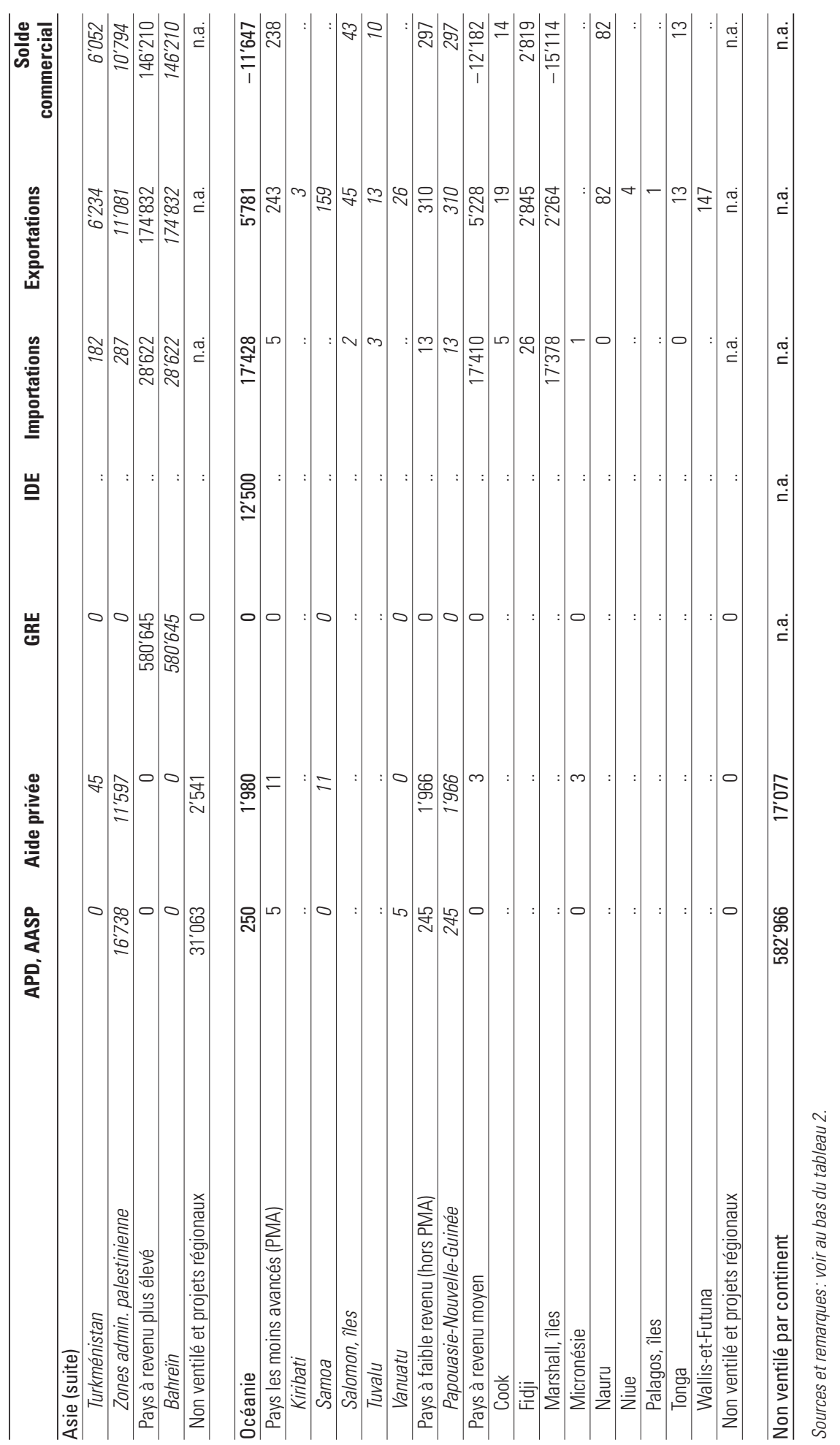




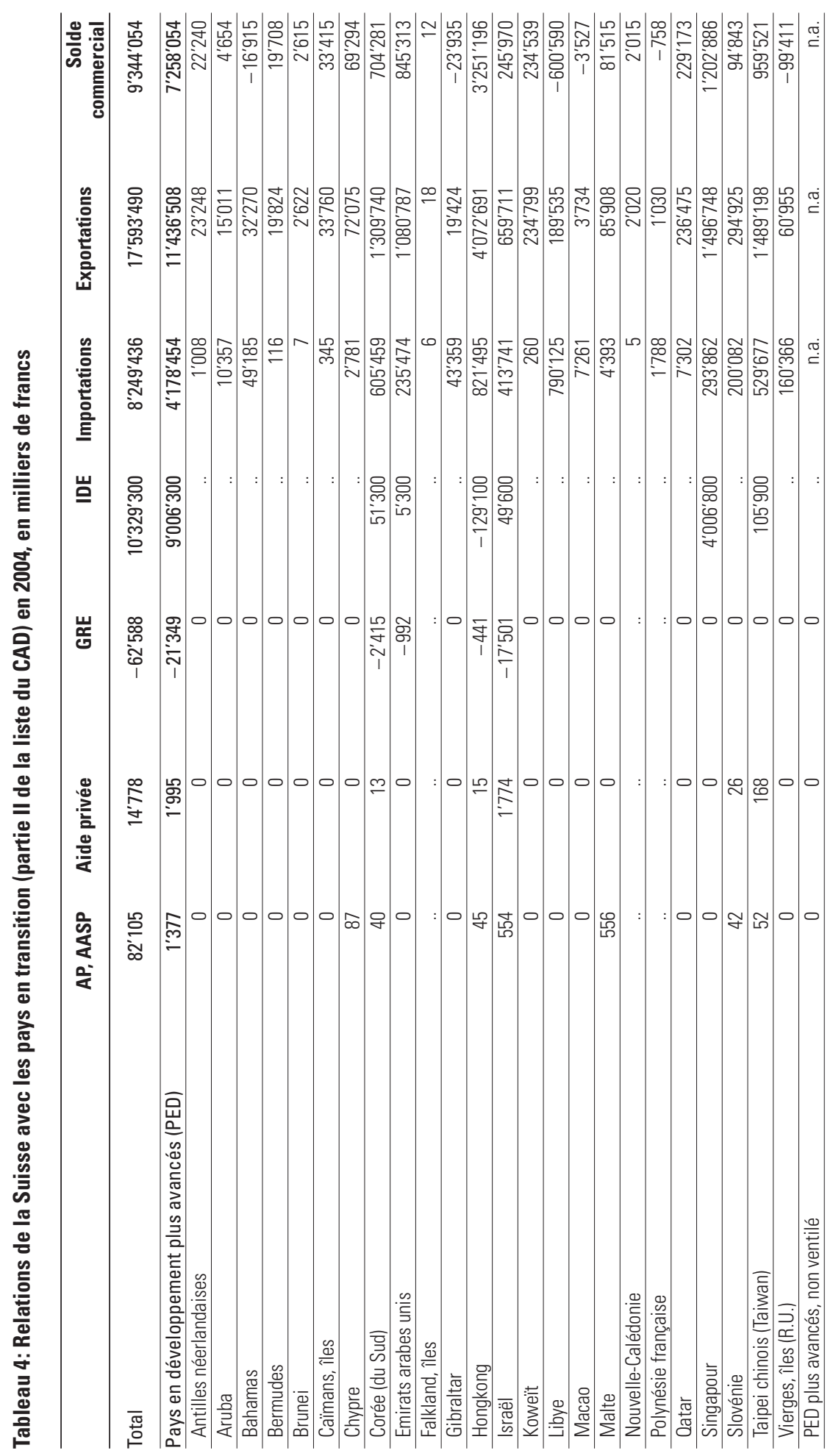




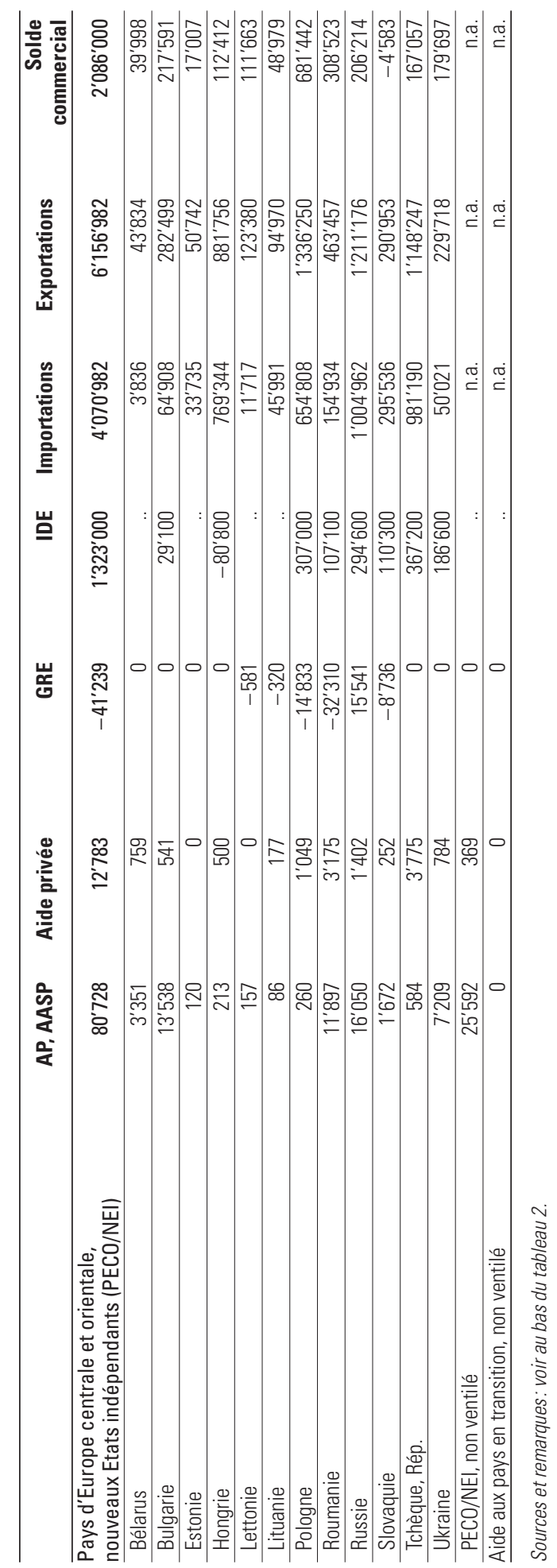

